\title{
Desenvolvimento de uma vacina tetravalente contra dengue*
}

Development of Sanofi Pasteur tetravalent dengue vaccine

Desarrollo de una vacuna tetravalente contra dengue

Bruno Guy

Departamento de Pesquisa e Desenvolvimento, Sanofi Pasteur, 69280, Marcy l'Etoile, France

\author{
Melanie Saville \\ Departamento de Pesquisa e Desenvolvimento, Sanofi Pasteur, 69280, \\ Marcy l'Etoile, France
}

João Bosco Siqueira Jr

Departamento de Epidemiologia e Saude Coletiva da Universidade Federal de Goiânia, Goiás, Brasil

Lucia Ferro Bricks

Departamento de Saúde Pública Vacinas, Sanofi Pasteur, Brasil

Jean Lang

Departamento de Pesquisa e Desenvolvimento, Sanofi Pasteur, 69280, Marcy l'Etoile, France

\section{RESUMO}

Este artigo é uma revisão sobre o desenvolvimento de uma vacina candidata tetravalente contra a dengue (VTD) composta por 4 cepas recombinantes vivas atenuadas de vírus da dengue. Cada cepa expressa os genes da pré-membrana (prM) e do envelope de um dos quatro sorotipos do vírus da dengue e tem como base a cepa da vacina febre amarela 17D (YF 17D). Os estudos pré-clínicos demonstraram que as cepas da VTD são estáveis genética e fenotipicamente, não hepatotrópicas, menos neurovirulentas do que a cepa YF 17D e não infectam mosquitos pela via oral. A VTD induz estimulação controlada das células dendríticas humanas e respostas imunes significantes. Estudos de Fase I foram realizados nos EUA, México e Filipinas. A soropositividade após 3 doses da VTD para os quatro vírus da dengue em pessoas naive a flavivírus foi de $100 \%$ nos adultos americanos e de 88 a 100\% em crianças mexicanas. Nos filipinos com imunidade prévia a flavivírus, observaram-se maiores taxas de soroconversão. Mais de 6 mil pessoas com idade entre $2 \mathrm{e}$ 45 anos já receberam pelo menos uma dose da VTD nos estudos de Fase l e ll. Todos os resultados disponíveis confirmam a imunogenicidade favorável e segurança da VTD em curto prazo. Em outubro de 2010, foi iniciado o programa de desenvolvimento final da vacina (Fase III), que deverá incluir milhares de pessoas residentes em países endêmicos, incluindo o Brasil, onde a doença é considerada um dos maiores desafios em saúde pública.

Palavras-chave: Vacinas contra dengue; Vírus da dengue; Flavivírus; Vacinas; Imunização.

*Este estudo é uma tradução com atualizações de artigo publicado pela Human Vaccines, cujo editor concedeu permissão em 25.10.2011 de publicação na RPAS. O artigo original foi publicado de acordo com a referência: Guy B, Saville M, Lang J. Development of Sanofi Pasteur tetravalent dengue vaccine. Hum Vaccin. 2010; 6(9):669-705.

\section{INTRODUÇÃO}

Várias espécies do gênero Flavivirus representam séria ameaça para a saúde humana e animal. Entre eles, os vírus da dengue representam um problema clínico importante e crescente. Todos os quatro sorotipos do vírus da dengue podem causar infecção em humanos, com ou sem sintomas. Nos casos sintomáticos, as manifestações clínicas variam de quadros leves e autolimitados até os

\footnotetext{
Correspondência / Correspondence / Correspondencia: Lucia F. Bricks

Diretora Saúde Pública Sanofi Pasteur, Divisão Vacinas do Grupo Sanofi, Brasil, Av. Sylvio de Magalhães Padilha, 5200. Jardim Morumbi

CEP: 01246-902 São Paulo-São Paulo-Brasil

Tel: + 55 (1 1 1 ) 3759 - 6260/(1 1) 91553913

E-mail: lucia.bricks@sanofipasteur.com
}

quadros típicos da febre da dengue, febre hemorrágica da dengue (FHD), síndrome do choque da dengue (SCD) ou dengue com complicações (DCC), que podem ter evolução fatal' .

O número de infecções por dengue em áreas endêmicas tem aumentado continuamente desde a década de 1990. A doença afeta mais de uma centena de países, colocando em risco mais de três bilhões de pessoas'. Estima-se que, anualmente, mais de 100 milhões de infecções por dengue resultem em 24 mil mortes e, na maioria dos países, as crianças são as mais afetadas pela doença. A incidência crescente e amplo alcance geográfico da dengue fazem com que o desenvolvimento de uma vacina eficaz contra essa doença seja considerado uma prioridade de saúde internacional ${ }^{2}$.

Os laboratórios acadêmicos e as empresas farmacêuticas têm desenvolvido diversas vacinas candidatas contra a dengue, utilizando diferentes 
tecnologias, como, por exemplo, vacinas contendo vírus vivos atenuados; vetores virais recombinantes que expressam os antígenos do envelope (E) do vírus da dengue; proteínas recombinantes; e vacinas de DNA. Entretanto, até o presente, nenhuma vacina contra a dengue foi registrada ${ }^{3,4,5}$. A vacina candidata desenvolvida pela Sanofi Pasteur é uma vacina tetravalente que contém vírus recombinantes atenuados e que tem como base a cepa da vacina 17D contra a febre amarela (YF17D). A tecnologia de base para produção dos vírus recombinantes que compõem a vacina contra a dengue da Sanofi Pasteur (também conhecida como ChimeriVax) teve origem na St. Louis University ${ }^{6}$ e foi aplicada por Guirakhoo et $a^{7}$ na Acambis Inc. (que agora faz parte da Sanofi Pasteur). Esta vacina candidata contra a dengue é imunogênica e segura em humanos e vem sendo avaliada em estudos de eficácia de larga escala.

Os vírus vacinais são organismos geneticamente modificados (OGM) e, desde as fases iniciais de pesquisa para o desenvolvimento da vacina, foram conduzidos numerosos estudos para sua caracterização pré-clínica e clínica, de acordo com os regulamentos específicos para vacinas que contêm $O G M$. Os instrumentos, estratégias de ensaios e pesquisas implementadas como parte de programa de pesquisa e desenvolvimento de vacinas contendo flavivírus recombinantes da Sanofi Pasteur foram descritos detalhadamente em outra revisão ${ }^{8}$ e, neste estudo, esses aspectos serão abordados de forma resumida.

\section{CONSTRUÇÃO DA VACINA TETRAVALENTE CONTRA A DENGUE}

Os vírus que compõem a vacina recombinante tetravalente foram construídos por meio da substituição dos genes que codificam as proteínas da pré-membrana (prM) e do envelope (E) da cepa utilizada na vacina de febre amarela (YF 17D 204) pelos respectivos genes de cada um dos quatro sorotipos da dengue. Trata-se, portanto, de uma vacina combinada, que contém as cepas recombinantes resultantes CYD1, CYD2, CYD3 e CYD4 em uma única preparação (CYD1 -4) 6,7,9 (Figura 1).

\section{AVALIAÇÃO PRÉ-CLÍNICA}

Antes de serem avaliadas em estudos clínicos, todas as vacinas candidatas devem ser submetidas a testes de segurança e imunogenicidade em estudos pré-clínicos. Para as vacinas contra a dengue, os testes podem ser realizados tanto in vitro, em células primárias ou adaptadas, incluindo células humanas, quanto in vivo, em modelos animais, particularmente os que utilizam primatas não humanos (PNH). Os estudos pré-clínicos foram desenhados para fornecer informações sobre a estabilidade fenotípica e genotípica das cepas incluídas nas vacinas candidatas, para avaliar o seu tropismo, estrutura, capacidade de multiplicação e risco de transmissão por mosquitos vetores, assim como para documentar aspectos específicos ligados ao uso de OGM. Todos esses fatores podem afetar de forma direta ou indireta a segurança e a imunogenicidade da vacina.

Além disso, é importante que a vacina contra dengue induza a imunidade protetora contra os quatro sorotipos virais circulantes.

A figura 2 apresenta os diferentes tipos de células e tecidos potencialmente afetados pelas vacinas contra a dengue, e a figura 3 mostra alguns tipos de estudos préclínicos que podem ser conduzidos para estudar as consequências de tais interações.

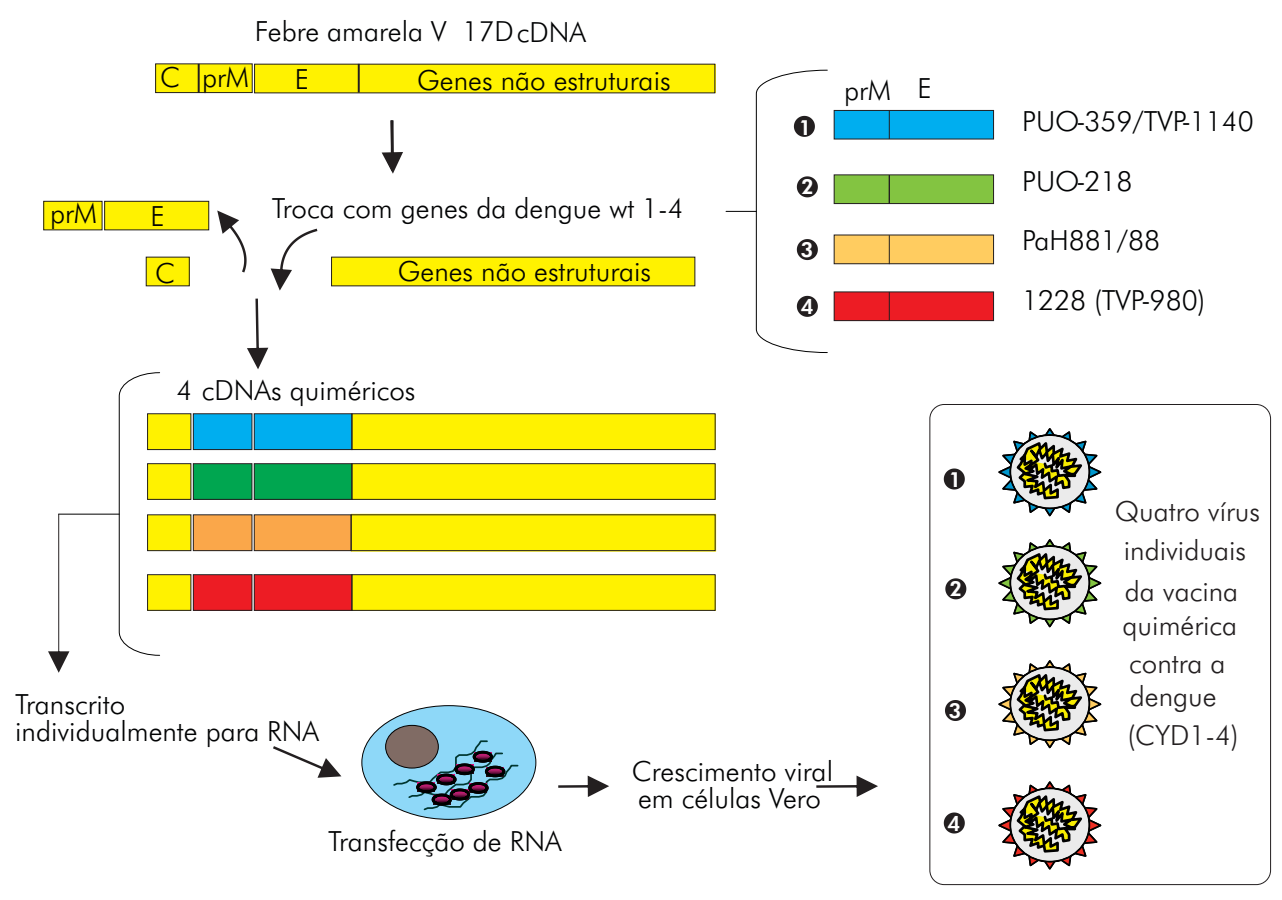

Figura 1- Desenvolvimento das quatro vacinas quiméricas 
Células endoteliais

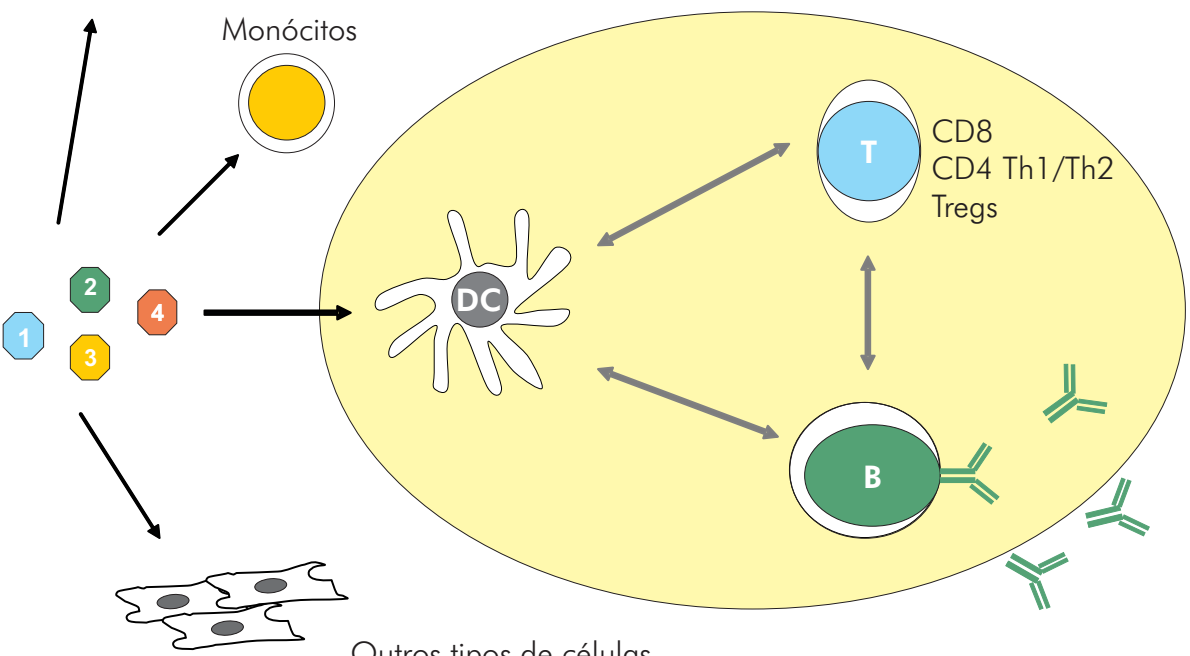

Outros tipos de células

(ou linhagens celulares in vitro)

Figura 2 - Respostas inatas e adaptativas potencialmente desencadeadas pelas vacinas candidatas contra a dengue. Após a vacinação, os vírus da vacina contra dengue podem se replicar preferencialmente em células da linhagem monocítica, tais como monócitos e células dendríticas (CDs). A apresentação do antígeno para as células CD4/CD8 T irá desencadear sua ativação e subsequente ativação das células B. A memória ativada das células B também pode ativar a potência das células apresentadoras de antígeno depois do reforço. Também é de interesse monitorar a possível replicação, e consequências, das vacinas contra a dengue em outros tipos de células, incluindo células endoteliais e células hepáticas

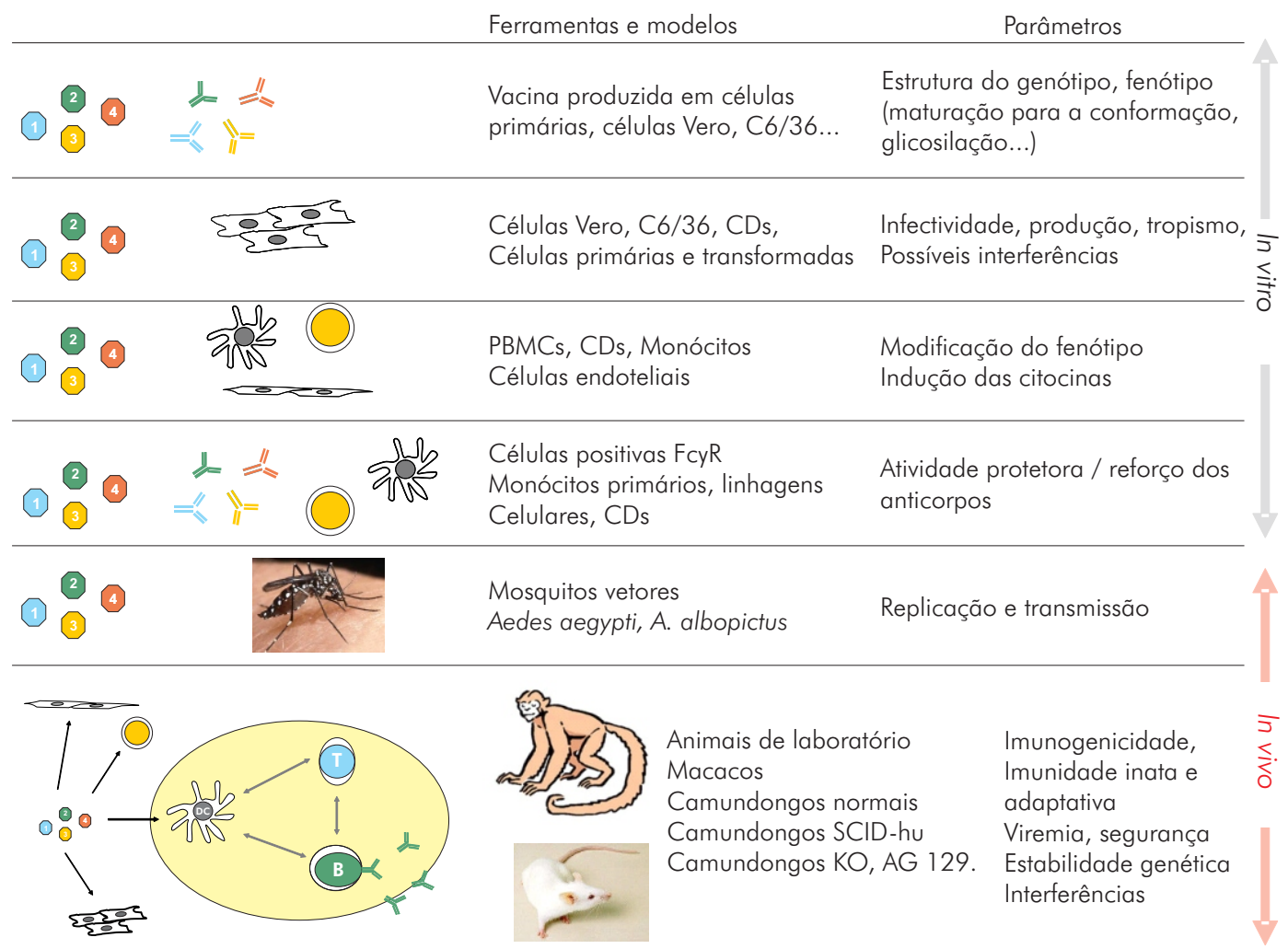

Figura 3 - Ensaios pré-clínicos usados para caracterizar as vacinas candidatas contra a dengue 


\section{Estabilidade genética in vitro}

O genoma do vírus YF 17D utilizado como base para o desenvolvimento dos vírus recombinantes (CYD) é bastante estável, tanto in vivo quanto in vitro ${ }^{10}$, fato que pode ser atribuído à baixa taxa de erro da RNA polimerase viral" Como essa enzima é a mesma que garante a multiplicação viral dos vírus $C Y D$, espera-se que esses vírus também apresentem alta estabilidade. A sequência completa do genoma de cada cepa CYD foi estabelecida em vários estágios durante a fabricação dos lotes da vacina, desde as primeiras etapas de produção até a fabricação dos lotes semente pré-mestre (LSPM), lotes semente mestre (LSM), vacina a granel (bulk) e, também, em etapa posterior ao processo de fabricação (produto bulk +10 passagens). Todas as quatro cepas CYD apresentaram alta estabilidade genômica durante todas as etapas de multiplicação em células, observando-se, no total, apenas nove mutações. Cinco mutações foram detectadas apenas em passagens tardias (entre p10 e p21), três destas ainda na fase de população mista e contendo a sequência original. Uma mutação foi silenciosa. Todas as mutações, exceto uma no gene $E$, estavam localizadas nas regiões não estruturais do genoma e, provavelmente, refletiam a adaptação dos vírus às células Vero. As mutações não silenciosas presentes nas etapas iniciais de fabricação apareceram durante a mudança de escala dos LSPM para LSM e permaneceram estáveis durante todo o processo (dados não publicados).

\section{Estabilidade fenotípica in vitro}

O sequenciamento do genoma não é apropriado para detectar a presença de quase-espécies em lotes semente da vacina e fornece poucas informações sobre as possíveis consequências biológicas de uma mutação específica. Entretanto, as mutações que afetam a eficiência da infecção, o crescimento, a penetração ou a disseminação dos vírus geralmente modificam o fenótipo da placa ${ }^{12,13}$. A uniformidade do fenótipo foi monitorada durante toda a produção dos lotes da vacina utilizando-se um teste para fenótipo de tamanho da placa. Estimou-se que, se fossem avaliadas pelo menos 100 placas por meio do teste de fenótipo, a probabilidade de detectar mutações em $2 \%$ das cepas seria superior a $90 \%$. Os fenótipos do tamanho das placas de todos os vírus CYD foram estáveis em todas as fases de produção.

A estabilidade fenotípica também foi avaliada em animais de laboratório, quando disponíveis (ver abaixo) ${ }^{14}$.

\section{Estudos pré-clínicos in vitro}

As células dendríticas da pele (CDs) estão entre as primeiras células a fazer frente ao vírus após a inoculação e são também as células apresentadoras de antígenos (APC) mais eficientes envolvidas na resposta imune primária. As interações entre as células dendríticas humanas e os vírus selvagens da dengue (wt) têm sido bem documentadas ${ }^{15,16}$, portanto, considerou-se interessante comparar as consequências imunológicas da infecção pelos vírus vacinais (CYD) com as obtidas após a infecção por cepas parentais wt. A infectividade das quatro cepas CYD foi investigada em CDs humanas derivadas de monócitos $^{17}$ e as consequências dessas infecções foram observadas por meio da avaliação da ativação e maturação celular e padrão de secreção de citocinas pró e anti-inflamatórias, quimiocinas e interferon tipo I (IFN II) ${ }^{18}$. Observou-se que os vírus CYD 1-4 induziram a maturação das DCs e uma resposta imune controlada, acompanhada pela produção limitada de citocinas inflamatórias e expressão uniforme do IFN I. Esses resultados foram posteriormente confirmados e ampliados com outros testes, como a técnica de DNA array profiling ${ }^{19}$.

O tropismo dos flavivírus está ligado principalmente à proteína $E$ do envelope, de modo que as cepas CYD não devem apresentar o mesmo tropismo que a cepa YF 17D. Para testar essa hipótese, a cinética do crescimento da CYD1-4 e dos vírus parentais (DEN-1, DEN-2, DEN-3 e DEN-4 selvagens e da cepa da vacina YF 17D) foi avaliada em três linhagens de células hepáticas, HepG2, Huh7 e THLE-3, como possível marcador para viscerotropismo. A multiplicação de todos os vírus quiméricos nas linhagens celulares HepG2 e THLE-3, foi muito menor do que a da cepa YF 17D (YF-VAX), fato este não observado na Huh7 ${ }^{17}$. As diferenças nos resultados entre as linhagens celulares podem ser explicadas pelo fato de que as células Huh7 permitem a multiplicação de muitos vírus, independentemente de sua atenuação. Esses resultados sugerem que os vírus CYD1-4 são menos hepatotrópicos do que o vírus da vacina YF 17D em humanos.

Diversos outros ensaios não descritos neste artigo foram utilizados para caracterizar melhor a vacina candidata CYD1-4. Dentre eles, incluem-se estudos com microscopia eletrônica para avaliar a maturidade viral; análise para avaliar a uniformidade do teor de proteína e do perfil proteico das vacinas, a condição de glicosilação (SDS/PAGE), a replicação em linhas celulares DC SIGN transfectadas, para avaliar a capacidade de as cepas das vacinas candidatas interagirem com esta molécula e, em seguida, efetivamente penetrarem nas células; a replicação em células C6/36 de insetos; e testes de sensibilidade à temperatura (dados ainda não publicados).

\section{Estudos pré-clínicos in vivo}

Foram utilizados modelos animais (camundongos e $\mathrm{PNH}$ ) para testar a neurovirulência e comparar o neurotropismo das cepas da vacina CYD1-4 com o observado após infecção pelas cepas parentais (dengue wt ou YF 17D). Um desses modelos, utilizando camundongos jovens (suckling mice), demonstrou ser uma boa alternativa para os modelos que utilizam $\mathrm{PNH}^{14}$. Após inoculação intracerebral em camundongos e $\mathrm{PNHs}$, todos os quatro vírus CYD mostraram-se significantemente atenuados, mesmo quando comparados com a cepa da vacina YF 17D. O modelo com camundongos lactentes agora é utilizado rotineiramente para testes de controle no processo de fabricação de vacinas contra flavivírus da Sanofi Pasteur que têm como base a vacina YF 17D.

Alguns PNHs, como os macacos rhesus (Macaca mulatta) e cynomolgus (Macaca fascicularis), são sensíveis à infecção por vírus da dengue e da febre amarela. A Organização Mundial de Saúde (OMS) reconhece essas 
espécies como bons modelos para a avaliação do neurotropismo e viscerotropismo das vacinas atenuadas de febre amarela (WHO Technical Report Series, No 872, 1998). A viremia pode ser usada para avaliar a atenuação das vacinas candidatas contra dengue, comparando-se a viremia das cepas recombinantes CYD com a observada após a infecção experimental por cepas parentais (dengue wt ou YF 17D).

Como os macacos infectados pela dengue não desenvolvem sintomas da doença, a viremia também pode ser usada para avaliar a proteção contra o desafio (inoculação experimental de vírus da dengue wt após vacinação), comparando-se a viremia dos vírus wł em animais vacinados e não vacinados (grupo controle). A redução da viremia wt em vacinados deve ser associada à proteção $^{20}$.

Como a viremia está associada à virulência e à gravidade da dengue em humanos, estudos para avaliar a viremia podem ser tanto marcadores diretos do tropismo das cepas, como indicadores indiretos de segurança ${ }^{20}$.

Os estudos com $\mathrm{PNH}$ s também podem ser usados para fornecer informações adicionais sobre a capacidade de as vacinas candidatas contra a dengue induzirem a formação de anticorpos neutralizantes ${ }^{9,21,22}$. Esses estudos, em particular, têm sido usados para explorar os parâmetros de imunização, tais como esquema de dosagem e formulação da vacina, e para monitorar a interferência viral entre os quatro vírus vacinais. É difícil estabelecer limiares absolutos aceitáveis para a imunogenicidade protetora e a viremia e, mesmo que esses limiares sejam estabelecidos por meio de estudos em modelos animais, eles não podem necessariamente ser extrapolados entre espécies de hospedeiros. Dessa forma, as respostas imunes e a viremia induzidas pelos vírus das vacinas candidatas contra dengue devem ser comparadas com aquelas induzidas pelos vírus selvagens. Os estudos com PNHs têm demonstrado que a imunização primária com a vacina CYD1-4 induziu viremia baixa e de curta duração após a primeira dose, mas não após as doses de reforço. Uma ou várias injeções da VTD conferiram imunidade contra os quatro sorotipos de DENV e proteção quase completa contra cada sorotipo após desafio com DENV $w^{9}$.

Como ocorre com qualquer vacina multivalente, o desenvolvimento da vacina contra a dengue é complicado pelo potencial de interferência entre sorotipos, que pode resultar em uma resposta imune dominante contra apenas um ou dois sorotipos. Em PNHs, a interferência foi observada após a vacinação com uma preparação tetravalente contendo $5 \log _{10} C C_{50}$ de cada vírus (designada 5555 e considerada como preparação de referência da vacina tetravalente) ${ }^{23}$. Foram identificadas diversas abordagens para minimizar a interferência:

I - administração simultânea de duas vacinas bivalentes complementares em sítios anatômicos separados, drenadas por diferentes nodos linfáticos;

II - administração sequencial de duas vacinas bivalentes complementares;
III - pré-imunização com um flavivírus heterólogo;

IV - adaptação de formulações por meio da redução da dose do sorotipo imunodominante (CYD-4);

V-administração da dose de reforço após um ano.

Esses estudos também mostraram que as imunizações devem ser espaçadas por vários meses para evitar interferência negativa - possivelmente resultante da produção de anticorpos de curta duração que apresentam reatividade cruzada ( $\operatorname{g} M)$, ativação de células $T$ com reatividade cruzada ou mesmo imunidade inata - e para permitir melhor indução de memória. Tais esquemas têm sido testados em humanos em diversos estudos, cujos resultados confirmaram a importância de administrar uma dose de reforço um ano após o início do esquema. Esses estudos também focalizaram as diferenças entre espécies, já que o intervalo entre a imunização sequencial com vacinas bivalentes complementares precisa ser mais longo em humanos do que em macacos (dados não publicados).

\section{AVALIAÇÃO DO RISCO AMBIENTAL}

Várias questões teóricas relacionadas à natureza dos vírus vivos CYD (OGM) e à segurança de vacinas que contêm OGM foram abordadas durante o desenvolvimento da VTD. As quatro preocupações mais frequentemente discutidas são: a transmissão dos vírus vacinais por artrópodes vetores, a recombinação com outros vírus circulantes, a reversão para virulência e os riscos de viscerotropismo ${ }^{8}$.

Para avaliar se os mosquitos que transmitem DENV e febre amarela poderiam ser infectados com os vírus CYD após picar um hospedeiro vacinado, foram realizados estudos para comparar a capacidade de multiplicação dos vírus CYDs em cultura de células de mosquitos Aedes albopictus (C6/36) e Aedes aegypti (principais vetores dos vírus da febre amarela e da dengue, respectivamente, com a capacidade de replicação das cepas YF 17D e vírus selvagens da dengue ${ }^{24}$. Os vírus CYD foram incapazes de infectar os mosquitos Ae. aegypti e Ae. albopictus por via oral e de se replicar no tecido do intestino médio desses mosquitos após inoculação intratorácica; além disso, mostraram-se mais atenuados do que os vírus YF 17D nessas espécies.

A ausência ou baixa e curta viremia das cepas CYD aliada à incapacidade de essas cepas infectarem e se replicarem em mosquitos vetores são salvaguardas críticas contra a disseminação desses vírus no ambiente ${ }^{24,25}$.

Com base em pressupostos teóricos e em analogia com vacinas que não contêm flavivírus, sugeriu-se que poderiam surgir novos vírus por meio da recombinação das cepas vacinais com flavivírus ou outros RNA-vírus ${ }^{26}$. Esses pressupostos foram contestados pela maioria dos especialistas na área ${ }^{27,28}$. Um estudo recente investigou a probabilidade de recombinação intermolecular entre diferentes flavivírus, usando pares de replicons derivados do vírus da encefalite por carrapatos (TBVE), vírus da encefalite japonesa (JEV) e vírus do oeste do Nilo (WNV) ${ }^{29}$. Os resultados desse estudo mostraram que foram 
detectados pouquíssimos eventos recombinantes (nenhum para TBEV ou WNV) e que todos esses vírus recombinantes eram aberrantes, tendo suas propriedades de crescimento prejudicadas. Os resultados desse estudo confirmaram que os flavivírus apresentam baixa propensão à recombinação homóloga e complementaram os dados de estudos anteriores que investigaram o que aconteceria na hipótese improvável da emergência de tais vírus recombinantes. Considerando-se como pior cenário a possibilidade de recombinação de uma das cepas vacinais (CYD) com um dos sorotipos selvagens de DENV ou YF (YF Asibi wt), todas as observações de replicação e transmissão em mosquitos, assim como os desfechos observados em PNHs, mostraram que as cepas recombinantes eram atenuadas em comparação com os vírus parentais selvagens ${ }^{30,31,32}$. Esses estudos também sugeriram que 0 próprio processo de recombinação contribuiu para a atenuação desses vírus. Assim, não apenas a recombinação dos vírus da vacina CYD com flavivírus selvagens é extremamente improvável, como seria improvável que qualquer recombinante causasse doença ou pudesse se disseminar.

Apesar da preocupação com o risco de mutações que poderiam levar à reversão para virulência, é praticamente impossível que as cepas CYD readquiram as propriedades do vírus selvagem da febre amarela, devido à estabilidade genética das cepas. Além de não possuírem os genes préM e E da cepa YF 17D, os vírus CYD apresentam diversos outros pontos de atenuação nos sete genes não estruturais da cepa YF 17D e no gene que codifica a proteína do cápside viral. Seriam necessárias reversões em todos estes genes para dar origem a um vírus virulento ${ }^{10,11}$.

Casos de doença viscerotrópica aguda após administração de vacinas que contêm a cepa YF 17D são extremamente raros (incidência estimada de 0,3 a 0,4 por 100 mil vacinados $)^{33}$. Apesar disso, existe alta percepção de risco para esse evento adverso sério, gerando preocupação sobre o risco de sua ocorrência após administração de vacinas contendo vírus CYD. Entretanto, deve-se enfatizar que o tropismo viral e a virulência das cepas estão, em grande parte, ligados à proteína $E$ e o gene que codifica o envelope do vírus da febre amarela YF 17D não está presente nos CYD. Além disso, os experimentos in vitro e os testes pré-clinicos in vivo demonstraram que o viscerotropismo e neurotropismo dos vírus CYD são significativamente atenuados em comparação com o observado após a administração da vacina YF 17D. Assim, é plausível propor que o perfil de segurança das vacinas quiméricas contra a dengue seja melhor em comparação com o da vacina YF 17D, particularmente com relação à maioria dos eventos adversos neurotrópicos.

\section{DESENVOLVIMENTO CLÍNICO}

As considerações e desafios relacionados ao desenvolvimento clínico das vacinas contra a dengue são:

I - Necessidade de induzir uma resposta imune adequada e equilibrada para os quatro sorotipos;
II - Necessidade de administrar duas ou três doses da vacina ao longo de um período de até 12 meses em indivíduos naive ao flavivírus;

III - Necessidade de demonstrar eficácia clínica, tendo em vista que não se conhecem correlatos de proteção para dengue;

IV - Necessidade de demonstrar segurança e imunogenicidade no longo prazo;

$V$ - Riscos teóricos de sensibilização para a infecção grave se os vacinados forem infectados por DENV selvagens da dengue, podendo desenvolver a FHD ou eventos adversos raros, como doença viscerotrópica aguda e doença neurotrópica aguda;

VI - Necessidade de seguir as diretrizes estabelecidas por órgãos regulatórios para pesquisas envolvendo $\bigcirc \mathrm{GM}$.

Um problema adicional é a diversidade de experiências imunológicas prévias com flavivírus, tanto por infecção por wt, como associada à vacinação prévia com as vacinas de febre amarela ou encefalite japonesa. Isto significa que será necessário conduzir estudos paralelos com a VTD em diferentes regiões do mundo, assim como avaliar sua coadministração com diferentes vacinas.

A vacina foi produzida de acordo com as diretrizes das Boas Práticas Clínicas e todos os regulamentos nacionais e internacionais aplicáveis, e os estudos clínicos estão sendo desenhados e conduzidos de acordo com as diretrizes da OMS para a Avaliação Clínica das Vacinas contra a Dengue em Áreas Endêmicas (OMS/IVB/08.12). A prioridade da Sanofi Pasteur foi desenvolver uma vacina contra a dengue para uso nos países endêmicos da ÁsiaPacífico, América Latina e Caribe, para preencher uma necessidade clínica não atendida, para crianças e adultos. Também serão realizados estudos em países europeus não endêmicos e nos EUA, para avaliar o uso da vacina para viajantes e militares.

\section{Avaliação clínica de fase I}

A primeira avaliação clínica de uma vacina candidata CYD foi realizada com uma vacina monovalente contendo o sorotipo CYD-2. O perfil de segurança dessa vacina CYD-2 foi similar ao da vacina controle YF 17D (YF-VAX $\left.{ }^{T M}\right)$, tendo sido constatado que a viremia após a vacinação foi baixa e transitória. A maioria dos participantes apresentou soroconversão para a cepa 16.681 do vírus da dengue, e verificou-se que as pessoas com imunidade prévia à cepa YF 17D apresentaram respostas imunes mais potentes, com maior espectro de proteção cruzada (crossprotection), e mais duradouras ${ }^{34}$.

primeiro estudo mostrando soroconversão apropriada para os quatro sorotipos da dengue [teste de PRNT $50 \geq 10$ ] foi realizado nos EUA, em adultos denguenaive vacinados com três doses da VTD (CYD 1-4), no esquema 0 (dose inicial), 3,5 e 12 meses ou com duas doses, com intervalo de 8 a 9 meses $^{25}$.

perfil de segurança da vacina VTD foi bastante favorável; a viremia foi baixa, constatada principalmente 
para a cepa CYD-4 após a primeira dose da vacina. Após a segunda dose, a viremia foi muito rara para todos os sorotipos vacinais, tanto pelo teste RT-PCR como pelas análises de placa (AP). Após a segunda dose da vacina CYD1-4, a maioria dos vacinados (> 85\%) também não apresentou viremia detetável para os sorotipos CYD-1, CYD-2 e CYD-3. (Tabela 1). Esses achados têm implicações significantes para a segurança desta vacina, pois mostraram que, mesmo quando a primeira dose da VTD não induziu soroconversão completa para os sorotipos 1, 2 e 3, a presença de anticorpos heterólogos contra o sorotipo DEN-4 (imunodominante) não desencadeou o fenômeno de sensibilização. Todos os participantes que receberam três doses da VTD CYDl-4 apresentaram soroconversão para os quatro sorotipos DENV de referência da OMS testados (Figura 4).

Tabela 1 - Eventos adversos (EA) observados após a administração da vacina VTD em voluntários naive ${ }^{25}$

\begin{tabular}{|c|c|c|c|c|c|}
\hline \multicolumn{2}{|c|}{$\begin{array}{l}\text { V1 } \\
\text { DO }\end{array}$} & \multicolumn{2}{|c|}{$\begin{array}{l}\text { V2 } \\
\text { M4 }\end{array}$} & \multicolumn{2}{|c|}{$\begin{array}{l}\text { V3 } \\
\text { M12 }\end{array}$} \\
\hline $\begin{array}{c}\text { Grupo } 1 \\
1^{a} \text { VTD } \\
(\mathrm{N}=33) \\
\mathrm{n}(\%)\end{array}$ & $\begin{array}{c}\text { Grupo } 2 \\
\text { Placebo } \\
(\mathrm{N}=33) \\
\mathrm{n}(\%)\end{array}$ & $\begin{array}{c}\text { Grupo } 1 \\
2^{\mathrm{a}} \text { VTD } \\
(\mathrm{N}=30) \\
\mathrm{n}(\%)\end{array}$ & $\begin{array}{c}\text { Grupo } 2 \\
1^{a} \text { VTD } \\
(\mathrm{N}=33) \\
\mathrm{n}(\%)\end{array}$ & $\begin{array}{c}\text { Grupo } 1 \\
3^{a} \text { VTD } \\
(\mathrm{N}=23) \\
\mathrm{n}(\%)\end{array}$ & $\begin{array}{c}\text { Grupo } 2 \\
2^{a} \text { VDT } \\
(\mathrm{N}=26) \\
\mathrm{n}(\%)\end{array}$ \\
\hline $28(84,8)$ & $22(66,7)$ & $24(80,0)$ & $24(72,7)$ & $15(65,2)$ & $17(65,4)$ \\
\hline $27(81,8)$ & $20(60,6)$ & $21(70,0)$ & $21(63,6)$ & $10(43,5)$ & $17(65,4)$ \\
\hline $6(18,2)$ & $5(15,2)$ & $11(36,7)$ & $8(24,2)$ & $4(17,4)$ & $7(26,9)$ \\
\hline $26(78,8)$ & $19(57,6)$ & $20(66,7)$ & $18(54,5)$ & $10(43,5)$ & $16(61,5)$ \\
\hline $6(18,2)$ & $2(6,1)$ & $1(3,3)$ & $4(12,1)$ & $0(0,0)$ & $0(0,0)$ \\
\hline $5(15,2)$ & $2(6,1)$ & $1(3,3)$ & $4(12,1)$ & $0(0,0)$ & $0(0,0)$ \\
\hline $0(0,0)$ & $0(0,0)$ & $0(0,0)$ & $0(0,0)$ & $0(0,0)$ & $0(0,0)$ \\
\hline $5(15,2)$ & $2(6,1)$ & $1(3,3)$ & $4(12,1)$ & $0(0,0)$ & $0(0,0)$ \\
\hline
\end{tabular}
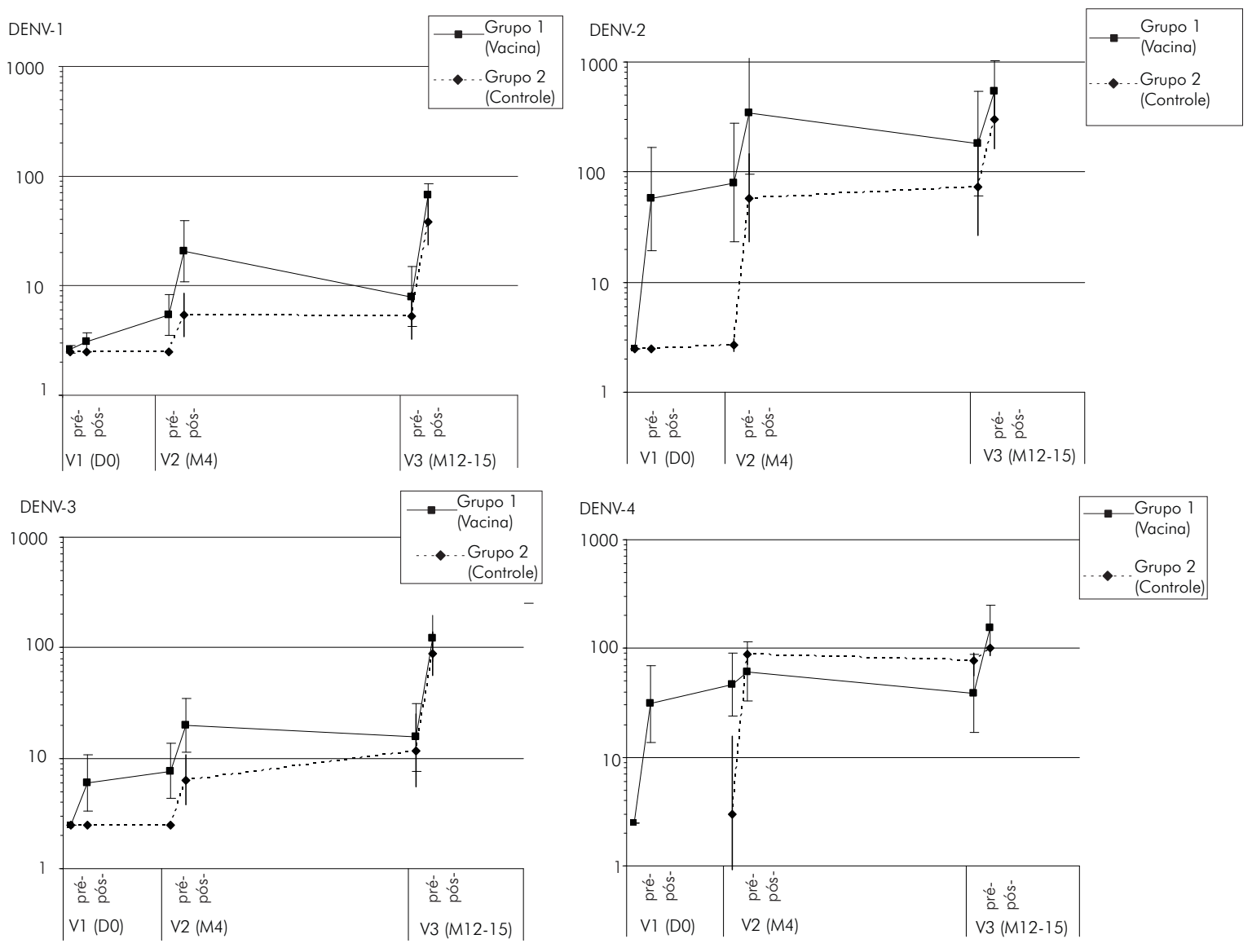

Figura 4 - MGT ( $\log _{10}$ com IC 95\%, cepas de referência da OMS) em voluntários sem imunidade prévia a flavivirus (naive), obtida após uma a três doses da VTD ${ }^{25}$ Grupo 1 : três doses da VDT administrada no dia 0 (D0) e meses 4 (M4) e 12 (M12). Grupo 2: uma dose de placebo administrada no dia 0 (D0), seguida por duas doses da VDT administradas nos meses M4 e M12. Foram coletadas amostras de sangue antes de cada dose da vacina e 28 dias pós-vacinação 
Foi evidente a relação entre número de doses e a resposta imune: tanto a média geométrica dos títulos de anticorpos (MGT) quanto a porcentagem de participantes que apresentaram soroconversão para os quatro sorotipos aumentaram após cada vacinação. A primeira dose da VTD induziu anticorpos neutralizantes principalmente contra DENV-2 e DENV-4, e, em menor extensão, contra DENV-1 e DENV-3. Após a segunda e terceira doses, aumentou a porcentagem de participantes com soroconversão para os quatro sorotipos, assim como as MGTs de anticorpos neutralizantes para todos os sorotipos, equilibrando a resposta imune aos quatro sorotipos (MGT de 67,538, 122 e 154 em relação aos sorotipos DEN-1, DEN-2, DEN-3 e DEN-4, respectivamente).

Além disso, foi observada uma tendência de serem as MGTs e as taxas de soroconversão mais altas após duas doses da VTD nos voluntários que receberam essas doses com intervalo de 8 a 9 meses, ao invés de receberem a segunda dose após 3 meses (especialmente para DENV-1 e DENV-3). Esta última observação confirmou o que já havia sido constatado em macacos imunizados com a mesma VTD e que apresentaram respostas imunes marcantes contra todos os sorotipos quando o intervalo entre segunda e terceira doses da vacina foi de 10 meses, porém não quando o intervalo foi de apenas 2 meses $^{23}$. Neste estudo clínico, também foram monitoradas a respostas imunes celulares, observando-se que a natureza das respostas celulares inata e adaptativa (perfil das citocinas, desvio para resposta CD8/Th, imunodominância) foram favoráveis e compatíveis com o perfil de segurança e dados de imunogenicidade humoral.

Os estudos de acompanhamento com o mesmo esquema de vacinação descrito acima foram realizados em indivíduos com idades entre 2 e 45 anos residentes em áreas não endêmicas (Cidade do México) e áreas endêmicas para dengue (Filipinas) ${ }^{35,36}$. Os achados desses estudos foram compatíveis com os do estudo realizado em adultos americanos ${ }^{25}$ e mostraram ainda que: a imunidade prévia a flavivírus (YD 17D no México ou encefalite japonesa e DENV nas Filipinas) teve um impacto positivo na imunogenicidade da vacina contra a dengue sem quaisquer efeitos negativos sobre sua segurança; três doses da VTD no esquema 0, 3, 5 e 12 meses induziram respostas robustas de anticorpos contra os quatro sorotipos; e o registro de viremia das cepas vacinais foi uniformemente baixo para todos os sorotipos e, geralmente, menor do que o limite inferior de quantificação dos testes utilizados (como PCR e provas de placa) em todas as populações.

Em um terceiro estudo, desenvolvido com adultos australianos, a imunidade prévia contra os DENV-1 e DENV-2 resultante da vacinação com uma vacina candidata contra a dengue contendo vírus vivos atenuados (desenvolvida pela Mahidol University, Bangkok, Tailândia) serviu de estímulo (priming) para uma resposta imune mais forte e de maior espectro à VTD para os quatro sorotipos ${ }^{37}$.

Outra questão relevante é avaliar o risco potencial de que os vírus circulantes escapem da imunidade induzida pela vacina. A capacidade de neutralização cruzada de soros de macacos imunizados com CYD foi testada em um amplo painel de cepas de vírus wt da dengue, coletados recentemente em diferentes áreas endêmicas ${ }^{38}$. Os resultados obtidos indicaram que os anticorpos induzidos pela vacina protegem contra ampla gama de cepas de DENV de origens geográficas diversas. Análises similares estão sendo realizadas com soro de humanos.

Até o presente, a VTD tem demonstrado um perfil de segurança bastante satisfatório. Nos estudos acima citados, não foi identificado nenhum evento adverso sério (EAS) relacionado com a vacinação ${ }^{25,35,36,37}$. Diferentemente de outras vacinas candidatas contendo vírus vivos atenuados, os CYD não parecem induzir quadros semelhantes ao da febre da dengue associada à presença de viremia ${ }^{4}$. Os dados relativos à segurança e reatogenicidade desta vacina foram similares aos das vacinas utilizadas como controle. Não houve aumento nem de reatogenicidade pela presença de imunidade prévia aos DENV ou à febre amarela, nem nas reações após a segunda ou terceira doses da vacina, em comparação com a primeira dose.

A proteção contra a dengue está associada às respostas imunes humoral e celular; entretanto, essas respostas também estão envolvidas na imunopatologia das formas graves da dengue ${ }^{39}$. Em relação à imunidade humoral, é motivo de preocupação a hipótese de que um dos mecanismos responsáveis pelo aparecimento de formas graves da doença poderia estar relacionado a um aumento na replicação viral em indivíduos com anticorpos heterotípicos não neutralizantes, conhecido como fenômeno ADE (antibody dependent enhancement ou reforço dependente de anticorpos) ${ }^{40,41}$. Este tema será tratado especificamente a seguir. Sob o aspecto da imunidade celular, as respostas imunes deveriam incluir respostas multivalentes homólogas contra todos os sorotipos da dengue, com predomínio da resposta Thle maior produção de IFN- $\gamma$ em relação ao TNF- $\alpha$. A resposta heteróloga de reação cruzada tende a desencadear a produção de TNF- $\alpha$ enquanto respostas homólogas desencadeiam a produção de IFN- $\gamma^{39,42,43}$.

As respostas imunes das células CD4 e CD8 contra os vírus parentais YF 17D e DENV induzidas por CYD1-4 foram avaliadas em voluntários com e sem imunidade pré-existente aos flavivírus ${ }^{44}$. A VTD não desencadeou alterações relevantes no perfil de citocinas próinflamatórias séricas, independentemente da condição imune basal, porém induziu resposta CD8 NS3-específica para a cepa YF 17D e respostas Th1 específicas para os DENV, com predomínio do IFN- $\gamma$ sobre o TNF- $\alpha$. Da mesma forma que para a imunidade humoral, as respostas celulares foram inicialmente dominadas pelo DEN-4 em indivíduos dengue-naive, porém as doses sequenciais da vacina ampliaram o espectro de respostas específicas para outros sorotipos. A resposta de mais amplo espectro também foi observada quando a VTD foi administrada em indivíduos com imunidade prévia aos DENV-1 e DENV-2. Os dados também revelaram ausência de reatividade cruzada entre as respostas à cepa YF 17D e respostas CD8 NS3-específica para os vírus da dengue, e possibilitaram a identificação de três novos epítopos no antígeno YF 17D NS3. De acordo com a 
hipótese do efeito Hoskin (original antigenic sin), respostas heterólogas CD8 anti-NS3 poderiam estar envolvidas na gravidade da infecção secundária heteróloga ${ }^{45}$. A reatividade cruzada entre os antígenos NS3 da cepa YF 17D e dos DENV foi praticamente ausente, indicando que nenhuma resposta indesejável cruzada anti-NS3 seria induzida pela cepa YF 17D expressando NS3 das cepas CYD. Infecções naturais subsequentes poderiam reforçar a resposta imune específica aos vírus da dengue, com um perfil imunológico não deletério ${ }^{39,42,43}$.

Do ponto de vista prático, devemos mencionar que, para realizar esses estudos, foi necessário coletar quantidades significativas de sangue (de 35 a $50 \mathrm{~mL}$ ), dificultando a realização desses testes em crianças. Atualmente está sendo avaliada a possibilidade de realizar essas análises laboratoriais utilizando uma quantidade limitada de sangue $(<3 \mathrm{~mL})$, para viabilizar a realização dos testes de avaliação da resposta imune em crianças pequenas.

\section{Avaliação clínica de Fase II e III}

Estudos clínicos de Fase II para avaliar a segurança e imunogenicidade da VTD estão sendo conduzidos em vários continentes em crianças, adolescentes e adultos com diferentes tipos de antecedente de infecção por flavivírus e histórico vacinal, assim como para investigar a coadministração com outra vacina de vírus atenuados (sarampo, caxumba, rubéola) em lactentes. Uma prova de conceito para eficácia faz parte de um estudo de Fase llb. Quatro mil crianças tailandesas com idade entre 4 e 11 anos deverão receber três injeções subcutâneas da VTD ou de uma vacina controle nos momentos 0,6 e 12 meses após a primeira dose e serão monitoradas para avaliar a eficácia contra a dengue virologicamente confirmada, independentemente da sua gravidade. Estudos de Fase III de grande porte serão conduzidos em crianças e adolescentes na Ásia e América Latina ${ }^{46}$.

De acordo com as diretrizes da OMS, em cada fase do desenvolvimento clínico muitos indivíduos deverão ser acompanhados no longo prazo (3 a 5 anos). Isto permitirá monitorar a segurança no longo prazo, inclusive o potencial para dengue grave, e avaliar a persistência dos anticorpos e a possível necessidade de dose de reforço ${ }^{47}$.

\section{FENÔMENO AED}

A etiologia da FHD parece ser multifatorial. Se a hipótese AED é ou não um dos fatores associados à FHD in vivo ainda é um objeto de debates ${ }^{8}$. Apesar das controvérsias sobre o tema, a preocupação com esse fenômeno foi motivo de estudos desde o início das pesquisas relacionadas ao desenvolvimento de vacinas contendo CYD. Os pesquisadores da Sanofi Pasteur desenvolveram uma prova in vitro, sensível e reprodutível, usando células FcyRII da linhagem K562-positivas e citometria de fluxo para avaliar esse risco. $O$ soro de crianças tailandesas previamente vacinadas com uma vacina candidata de primeira geração, contendo DENV atenuados, foi testado com esses métodos, demonstrandose risco baixo ou ausente do fenômeno ADE in vitro, em crianças com diversos perfis sorológicos, com títulos baixos e altos de anticorpos não neutralizantes contra um ou vários sorotipos da dengue ${ }^{47}$. In vitro, não foi observado o fenômeno ADE na presença de ampla resposta neutralizante contra os quatro sorotipos de DENV. Assim, qualquer que seja o papel do ADE na etiologia de dengue grave in vivo, uma vacina capaz de induzir uma resposta neutralizante contra os quatro sorotipos (prova de conceito) deve evitar esse problema.

Conforme as diretrizes da OMS, há um consenso de que o desenvolvimento clínico das vacinas contra a dengue não deve ser prejudicado por certas preocupações hipotéticas com a segurança ${ }^{48}$. A etapa seguinte dos grandes estudos de eficácia com um tamanho de amostra de vários milhares (Fase III) já foi iniciada e, até abril de 2011, mais de 6 mil pessoas já tinham recebido, pelo menos, uma dose da vacina candidata da Sanofi Pasteur, não tendo sido observado nenhum sinal de segurança nos estudos já completados ou em andamento. Os estudos de Fase III fornecerão mais evidências sobre quaisquer questões de segurança que ocorram nos vacinados versus controles. Entretanto, a avaliação da possível relação causal ou casual entre desfechos graves muito raros somente poderá ser avaliada por meio de estudos de Fase IV e de vigilância pós-comercialização, tanto para esta vacina candidata como para as outras em fase mais precoce de desenvolvimento ${ }^{46}$.

\section{DESAFIOS FUTUROS}

Além dos desafios diretos do desenvolvimento clínico, e à medida que a vacina VDT da Sanofi Pasteur entra na fase clínica III, é importante estabelecer metas adequadas. Outros desafios diferentes precisam ser enfrentados para garantir a concessão do registro da vacina e seu uso em campo.

\section{Imunologia e desafios da pesquisa não clínica}

É preciso entender melhor os mecanismos protetores induzidos pelas vacinas candidatas contra a dengue. Os dados de futuros estudos clínicos de eficácia podem ser usados para comparação com os resultados observados nos estudos pré-clínicos, assim como para estimar um possível correlato de proteção. Estudos de ponte (bridging) entre resultados de estudos realizados em $\mathrm{PNH}$ s e dados de proteção clínica podem facilitar o desenvolvimento de novas formulações ou tecnologias de vacinas, reduzindo a necessidade de estudos clínicos caros e demorados. Com isto em mente, justifica-se uma estratégia clara, focalizada na imunologia, para desenvolver ensaios robustos, de alto rendimento, padronizados, para auxiliar no desenvolvimento clínico.

Em primeiro lugar, há necessidade de provas de neutralização de sorotipos específicos de alto rendimento, bem como provas padronizadas, reprodutíveis, de imunidade mediada por células que possam ser usadas com pequenas quantidades de sangue, e assim serem adequadas para aplicação em estudos pediátricos (ver acima). Uma ampla série de questões relacionadas com a avaliação de respostas celulares foi discutida em 2007 em Bangcoc, durante a força-tarefa da OMS sobre a imunidade celular da dengue, resultando em 
recomendações gerais ${ }^{49}$. Foi declarado em particular que, embora não obrigatória para fins de registro, a documentação de tais respostas em estudos clínicos inclusive os de Fase III - seria recomendada e traria informações importantes relativas à segurança no curto e longo prazo e à imunogenicidade das vacinas candidatas.

Em segundo lugar, provas simples e confiáveis para examinar a cinética e a afinidade de ligação de anticorpos poderiam fornecer estimativas úteis sobre a avidez geral do soro contra preparações virais ou de proteína $E$ em nível policlonal. Esta abordagem já foi pesquisada por alguns investigadores e seria interessante comparar a avidez geral das respostas induzidas pela vacinação versus aquelas induzidas por infeccão, assim como comparar a avidez geral com resultados de anticorpos de neutralização. A isotipagem das subclasses lgG E específicas também pode ser de interesse, já que fatores como sua atividade de fixação de complemento poderiam ser importantes.

Em terceiro lugar, compreender os mecanismos de interferência entre os DENV pode levar a esquemas de vacinação mais simples, em comparação com o esquema atual em questão, que envolve doses múltiplas da vacina tetravalentes administradas de 6 a 12 meses. A pesquisa pré-clinica aplicada é, assim, necessária para: I) entender melhor os mecanismos de interferência envolvendo imunidade inata e/ou adaptativa em modelos in vitro e in vivo adequados (ex.: por meio do desenvolvimento das provas mencionadas acima), II) usar este conhecimento para desenvolver novos esquemas que requeiram menor número de doses em períodos curtos, e III) desenvolver novas estratégias de tecnologia de vacinas para aliviar interferências sem comprometer a imunogenicidade e segurança.

Em quarto lugar, os modelos de segurança não clínicos precisam ser mais explorados. Embora existam modelos satisfatórios com camundongos e $\mathrm{PNHs}$ para neurotropismo, falta um modelo semelhante para viscerotropismo. Tais modelos poderiam tanto imitar o perfil imune induzido pelo DENV e permitir uma comparação de segurança (não humana), biodistribuição e atividade protetora das vacinas candidatas contra dengue como, por outro lado, servir de modelos patogênicos verdadeiros para a dengue, embora esta última meta possa não ser atingida.

\section{Desafios institucionais e econômicos}

Até recentemente, o interesse e investimentos em pesquisas sobre dengue e vacinas contra esta doença eram significativamente menores do que para as "três grandes" doenças infecciosas (HIV/AIDS, malária, tuberculose). Entretanto, diante da crescente importância global da dengue, da globalização da informação e, talvez, da militância em relação ao aquecimento global e seus possíveis efeitos sobre a distribuição geográfica das doenças, o interesse sobre a dengue tem aumentado. Militância e incentivos ainda faltam para os pesquisadores das instituições acadêmicas, tanto para trabalhar sobre a dengue como para melhorar oportunidades de carreira na área. Isso poderia ser alcançado por meio de recursos específicos e concessões disponíveis para aplicação na pesquisa sobre a dengue. Tais recursos podem ser fornecidos por organizações governamentais e/ou não governamentais voltadas para a saúde ou fundações privadas tais como a Pediatric Dengue Vaccine Initiative (PDVI), que conta com programas de avaliações específicas e de acesso a vacinas contra a dengue.

A pesquisa sobre a dengue ainda não atingiu uma massa crítica em muitos países onde a doença é endêmica e está classificada entre as cinco principais preocupações de saúde pública. A PDVI, em colaboração com a Organização Panamericana de Saúde (OPAS) e a OMS, organizaram recentemente reuniões regionais sobre pesquisa da dengue, reunindo cientistas da Ásia e das Américas. Tais reuniões ajudam a reunir dados, identificar novos rumos e estabelecer sinergias úteis e redes para permitir aos cientistas e vacinologistas da dengue realizarem avanços significativos. Esforços como este precisam ser renovados, a fim de ajudar a estabelecer redes científicas regionais para países onde a dengue é endêmica. Além disso, são necessárias alianças globais mais fortes entre a OMS, OPAS, autoridades regulatórias nacionais, formadores de opinião importantes, cientistas de destaque, fundações privadas e especialistas no desenvolvimento de vacinas para compartilhar dados, regulações, gerenciamento de risco e exigências de registro, em um novo modelo de parceria além do paradigma habitual do privado versus público.

\section{SITUAÇÃO EPIDEMIOLÓGICA DA DENGUE NO BRASIL}

No Brasil, a dengue tem se apresentado como um dos principais problemas de saúde pública, com cerca de 2,5 milhões de casos prováveis da doença e 280 mil internações registrados entre 2007 e $2010^{50,51}$. Apesar de grandes investimentos e esforços por parte das autoridades de saúde, a incidência da doença continua alta e existem limitações para o controle da dengue no país ${ }^{52}$.

Até o ano de 2005, a epidemiologia da dengue apresentou dois padrões distintos no Brasil: ondas epidêmicas localizadas em grandes centros urbanos (1986 a 1993) e epidemias/circulação endêmica do vírus em todas as regiões do país (1994 a 2005) ${ }^{53}$. $\bigcirc$ ano de 2006 marcou o início de um novo cenário na epidemiologia da doença, caracterizada pela migração de gravidade para crianças, com ápice nas epidemias registradas no ano de 2008, em especial no Estado do Rio de Janeiro ${ }^{53,54}$. Essa mudança no padrão de ocorrência da doença refletiu a recirculação do sorotipo DENV2 no país.

Atualmente temos os sorotipos 1, 2 e 3 do vírus circulando em todas as regiões do Brasil e, a partir do segundo semestre de 2010, a introdução do DENV4 a partir da Região Norte, com disseminação para as Regiões Nordeste e Sudeste ${ }^{55}$. $\bigcirc$ cenário atual é de hiperendemicidade da doença e a sucessão de sorotipos predominantes determinou ciclos de grande transmissão de dengue no país, que atingiram seus picos em 1998 (DENV1), 2002 (DENV3), 2008 (DENV2) e 2010 (DENV1), conforme pode ser observado na figura 5. Esse cenário, acrescido da introdução do DENV4 e do aumento de 
formas graves da doença, inclusive em crianças, evidencia a necessidade de melhorias nas atividades de prevenção e controle, incluindo o desenvolvimento de novas tecnologias, entre as quais uma vacina eficaz contra a doença ${ }^{56}$.

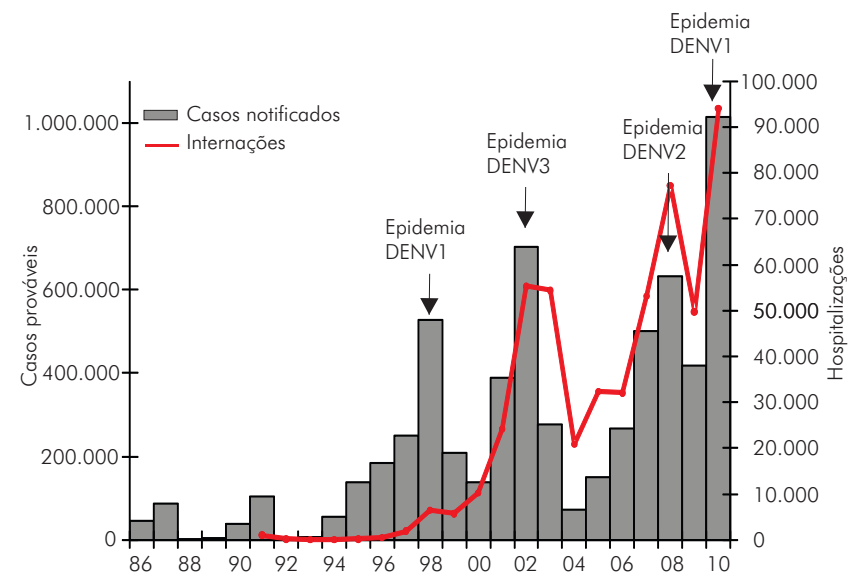

Figura 5 - Número de casos prováveis e de hospitalizações por dengue registrados no Brasil, no período de 1986 a 2010

\section{CONCLUSÃO}

A vacina candidata tetravalente recombinante de vírus atenuados contra a dengue da Sanofi Pasteur tem demonstrado segurança e imunogenicidade satisfatórias em testes pré-clínicos in vitro e in vivo, bem como em estudos clínicos em indivíduos naive e imunes a flavivírus. Os possíveis riscos associados aos vírus quiméricos têm sido avaliados em profundidade e a vacina tem demonstrado ser genética e fenotipicamente estável, não hepatotrópica, menos virulenta em comparação com a vacina contra a febre amarela 17D (YFV 17D) e incapaz de infectar mosquitos pela via oral. Até o início de 2011 , a vacina já havia sido administrada a mais de 6 mil crianças e adultos de áreas endêmicas e não endêmicas e nenhuma questão relativa à sua segurança havia sido detectada. $\bigcirc$ esquema de três doses induz respostas imunes humorais e celulares contra os quatro sorotipos na grande maioria dos vacinados e a presença de anticorpos contra flavivírus favorece resposta mais rápida e maiores títulos de anticorpos. Resultados preliminares de prova de conceito de eficácia são esperados para o final de 2012. 0 acompanhamento no longo prazo abordará questões de duração da imunidade e segurança contra eventos adversos muito raros. A obtenção de uma vacina eficaz e segura contra a dengue é uma necessidade para diversos países, incluindo o Brasil, onde a incidência da doença tem aumentado de forma dramática nos últimos anos. $\bigcirc$ início de estudos de eficácia (fase III) da vacina candidata da Sanofi Pasteur traz a esperança de que a proteção contra a dengue esteja em breve ao nosso alcance.

\section{AGRADECIMENTOS}

Os autores agradecem a Grenville Marsh pela assistência editorial, a todos os membros da antiga Acambis e da Sanofi Pasteur, assim como aos colaboradores externos envolvidos no desenvolvimento pré-clínico, clínico e industrial, particularmente Farshad Guirakhoo, Tom Monath, Steve Higgs, Sutee Yoksan, Veronique Barban, Anke Harenberg, Remi Forrat, Denis Crevat, Gustavo Dayan, Anh Wartel-Tram, Betzana Zambrano, Enrique Rivas e Rafaele Dumas. Agradecemos também a todos os investigadores, especialmente aos Drs. Dennis Morrison, Maria Rosario Capeding, Jorge Luis Poo, J. Qiao e D. Shaw, bem como aos voluntários envolvidos nos estudos clínicos.

\title{
Development of Sanofi Pasteur tetravalent dengue vaccine
}

\begin{abstract}
The Sanofi Pasteur tetravalent dengue vaccine candidate is composed of 4 recombinant live attenuated vaccines based on a yellow fever vaccine 17D (YFV 17D) backbone, each expressing the prM and envelope genes of one of the four dengue virus serotypes. Pre-clinical studies have demonstrated that the TV dengue vaccine is genetically and phenotypically stable, non-hepatotropic, less neurovirulent than YFV 17D and does not infect mosquitoes by the oral route. In vitro and in vivo preclinical studies also showed that the TV dengue vaccine induced controlled stimulation in human dendritic cells, and significant immune responses in monkeys. TV dengue vaccine reactogenicity, viraemia induction and antibody responses were investigated in three Phase I trials in the USA, the Philippines and Mexico, in a two or three-dose regimen over a 12 month period. Results showed that the majority of adverse events were mild to moderate and transient in nature. Viraemia was transient and low, and was not increased after initial dengue TV administration, even in the case of incomplete responses. Seropositivity [ $\geq 10$ in a PRNT 50 assay] was 100\% for all four serotypes in flavivirus-naive adults injected with 3 doses of TV dengue vaccine in the USA. Similarly, seropositivity was 88-100\% following three administrations in flavivirusnaive Mexican children aged 2-5 years. Furthermore, the proportion of seropositive subjects increased with each dengue TV injection in the Philippines where baseline flavivirus immunity was high. Responses were also monitored at the cellular level in humans, and their level and nature were in good agreement with the observed safety and the immunogenicity of the vaccine. Finally, the challenges inherent to the development of such TV dengue vaccines will also be discussed in the last part of this review. In conclusion, preclinical and clinical results support the favorable immunogenicity and short-term safety of the dengue TV vaccine. The final stage of development of the VTD (Phase III) started in October 2010 and will comprise thousands of individuals living in endemic countries, such as Brazil, where dengue is considered one of the biggest challenges in public health.
\end{abstract}

Keywords: Dengue; Vaccine; Human; Development; Immunity. 


\section{Desarrollo de una vacuna tetravalente contra dengue RESUMEN}

Este artículo es una revisión sobre el desarrollo de una vacuna candidata tetravalente contra el dengue (VTD) compuesta por 4 cepas recombinantes vivas atenuadas de virus de dengue. Cada cepa expresa los genes de la premembrana (prM) y del cierre de uno de los cuatro serotipos del virus del dengue y tiene por base la cepa de la vacuna de la fiebre amarilla 17D (YF 17D). Los estudios preclínicos demostraron que las cepas de la VTD son estables genética y fenotípicamente, no hepatotrópicas, menos neurovirulentas que la cepa YF 17D y no infectan a mosquitos por la vía oral. La VTD induce estímulo controlada de las células dendríticas humanas y respuestas inmunes significativas. Estudios de Fase I se realizaron en los Estados Unidos, México y Filipinas. La seropositividad luego de tres dosis de la VTD para los cuatro virus del dengue en personas naive a flavivirus fue de $100 \%$ en los adultos norteamericanos y de 88 a $100 \%$ en niños mexicanos. En los filipinos con inmunidad previa a flavivirus, se observaron mayores tasas de seroconversión. Más de 6 mil personas con edades entre 2 y 45 años ya han recibido al menos una dosis de la VTD en los estudios de Fase I y II. Todos los resultados disponibles confirman la inmunogenicidad favorable y la seguridad de la VTD a corto plazo. En octubre de 2010, se inició el programa de desarrollo final de la vacuna (Fase III), que deberá incluir a miles de personas residentes en países endémicos, incluyendo a Brasil, en donde la enfermedad está considerada como uno de los más grandes desafíos en salud pública.

Palabras clave: Vacunas contra dengue; Virus del dengue; Flavivirus, Vacunas; Inmunización.

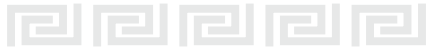

\section{REFERÊNCIAS}

1 Halstead SB. Dengue. Lancet. 2007 Nov;370(9599): 1644-52.

2 Reiter P. Yellow fever and dengue: a threat to Europe? Euro Surveill. 2010 Mar;15(10): 19509.

3 Raviprakash K, Defang G, Burgess T, Porter K. Advances in dengue vaccine development. Human Vaccin. 2009 Aug;5:520-8.

4 Whitehead SS, Blaney JE, Durbin AP, Murphy BR. Prospects for a dengue virus vaccine. Nat Rev Microbiol. 2007 Jul;5(7):518-28.

5 Guy B, Almond JW. Towards a dengue vaccine: progress to date and remaining challenges. Comp Immunol Microbiol Infect Dis. 2008 Mar;31(23):239-52.

6 Chambers TJ, Nestorowicz A, Mason PW, Rice CM. Yellow fever/Japanese encephalitis chimeric viruses: construction and biological properties. J Virol. 1999 Apr;73(4):3095-101.

7 Guirakhoo F, Weltzin R, Chambers TJ, Zhang ZX, Soike $K$, Ratterree $M$, et al. Recombinant chimeric yellow fever-dengue type 2 virus is immunogenic and Protective in Nonhuman primates. J Virol. 2000 Jun;74(12):5477-85.

8 Guy B, Guirakhoo F, Barban V, Higgs S, Monath TP, Lang J. Preclinical and clinical development of YFV 17D-based chimeric vaccines against dengue, West Nile and Japanese encephalitis viruses. Vaccine. 2010 Jan;28(3):632-49.

9 Guirakhoo F, Pugachev K, Zhang Z, Myers G, Levenbook I, Draper K, et al. Safety and efficacy of chimeric yellow fever-dengue virus tetravalent vaccine formulations in nonhuman primates. J Virol. 2004 May;78(9):4761-75.
10 Barban V, Girerd Y, Aguirre M, Gulia S, Pétiard F, Riou P, et al. High stability of yellow fever 17D-204 vaccine: a 12 -year restrospective analysis of large-scale production. Vaccine. 2007 Apr;25(15):2941-50.

11 Pugachev KV, Guirakhoo F, Ocran SW, Mitchell F, Parsons M, Penal C, et al. High fidelity of yellow fever virus RNA polymerase. J Virol. 2004 Jan;78(2): 1032-8.

12 Miller BR, Atkins D. Biological characterization of plaque-size variants of yellow fever virus in mosquitoes and mice. Acta Virol. 1988 May;32(3):227-34.

13 Vlaycheva LA, Chambers TJ. Neuroblastma cell-adapted yellow fever 17D virus: characterization of a viral variant associated with persistent infection and decreased virus spread. J Virol. 2002 Jun;76(12):6172-84.

14 Monath TP, Myers GA, Beck RA, Knauber M, Scappaticci K, Pullano T, et al. Safety testing for neurovirulence of novel live, attenuated flavivirus vaccines: infant mice provide an accurate surrogate for the test in monkeys. Biologicals. 2005 Sep;33(3): 131 44.

15 Libraty DH, Pichyangkul S, Ajariyakhajorn C, Endy TP, Ennis FA. Human dendritic cells are activated by dengue virus infection: enhancement by gamma interferon and implications for disease pathogenesis. J Virol. 2001 Apr;75(8):3501-8.

16 Palmer DR, Sun P, Celluzzi C, Bisbing J, Pang S, Sun W, et al. Differential effects of dengue virus on infected and bystander dendritic cells. J Virol. 2005 Feb;79(4):2432-9.

17 Brandler S, Brown N, Ermak TH, Mitchell F, Parsons M, Zhang Z, et al. Replication of chimeric yellow fever virus-dengue serotype 1-4 virus vaccine strains in dendritic and hepatic cells. Am J Trop Med Hyg. 2005 Jan;72(1):74-81. 
18 Deauvieau F, Sanchez V, Balas C, Kennel A, Montfort A, Lang $J$, et al. Innate immune responses in human dendritic cells upon infection by chimeric yellow fever dengue vaccines serotype 1-4. Am J Trop Med Hyg. 2007 Jan;76(1): 144-54.

19 Balas C, Kennel A, Deauvieau F, Sodoyer R, ArnaudBarbe N, Lang J, et al. Different innate signatures induced in human monocyte-derived dendritic cells by wild-type dengue 3 virus, attenuated but reactogenic dengue 3 vaccine virus, or attenuated nonreactogenic dengue 1-4 vaccine virus strains. J Infect Dis. 2011 Jan;203(1):103-8.

20 Vaughn DW, Green S, Kalayanarooi S, Innis BL, Nimmannitya S, Suntayakorn S, et al. Dengue viremia titer, antibody response pattern, and virus serotype correlate with disease severity. J Infect Dis. 2000 Jan;181(1):2-9.

21 Eckels KH, Dubois DR, Putnak R, Vaughn DW, Innis BL, Henchal EA, et al. Modification of dengue virus strains by passage in primary dog kidney cells: preparation of candidate vaccines and immunization of monkeys. Am J Trop Med Hyg. 2003;69(6 Suppl): 12-16. Erratum in: Am J Trop Med Hyg 2004 Dec;70:336-37.

22 Robert PJ, Coller BA, Voss G, Vaughn DW, Clements D, Peters l, et al. An evaluation of dengue type-2 inactivated, recombinant subunit, and live-attenuated vaccine candidates in the rhesus macaque model. Vaccine. 2005 Aug;23(35):4442-52.

23 Guy B, Barban V, Mantel M, Aguirre M, Gulia S, Pontvianne J, et al. Evaluation of interferences between dengue vaccine serotypes in a monkey model. Am J Trop Med Hyg. 2009 Feb;80(2):302- 11.

24 Higgs S, Vanlandingham DL, Klingler KA, McElroy KL, McGee CE, Harrington L, et al. Growth characteristics of ChimeriVax-Den vaccine viruses in Aedes aegypti and Aedes albopictus from Thailand. Am J Trop Med Hyg. 2006 Nov;75(5):986-93.

25 Morrison D, Legg TJ, Billings CW, Forrat R, Yoksan S, Lang J. A novel tetravalent dengue vaccine is well tolerated and immunogenic against all 4 serotypes in flavivirus-naive adults. J Infect Dis. 2010 Feb;201 (3):370-7.

26 Seligman SJ, Gould EA. Live flavivirus vaccines: reasons for caution. Lancet. 2004 Jun;363(9426):2073-5.

27 Monath TP, Kanesa-Thasan N, Guirakhoo F, Pugachev $\mathrm{K}$, Almond J, Lang J, et al. Recombination and flavivirus vaccines: a commentary. Vaccine. 2005 Apr;23(23):2956-8.

28 Hombach J, Kurane I, Wood D. Arguments for live flavivirus vaccines. Lancet. 2004 Aug;364(9433):4989.

29 Taucher C, Berger A, Mandl CW. A transcomplementing recombination trap demonstrates a low propensity of flaviviruses for intermolecular recombination. J Virol. 2010 Jan;84(1):599-611.
30 McGee CE, Tsetsarkin K, Vanlandingham DL, McElroy KL, Lang J, Guy B, et al. Substitution of wild-type yellow fever Asibi sequences for 17D vaccine sequences in ChimeriVax-dengue 4 does not enhance infection of Aedes aegypti mosquitoes. J Infect Dis. 2008 Mar; 197(5):686-92.

31 McGee CE, Lewis MG, Claire MS, Wagner W, Lang J, Guy B, et al. Recombinant chimeric virus with wild-type dengue 4 virus premembrane and envelope and virulent yellow fever virus Asibi backbone sequences is dramatically attenuated in nonhuman primates. J Infect Dis. 2008 Mar; 197(5):693-7.

32 Santos CN, Post PR, Carvalho R, Ferreira II, Rice CM, Galler R. Complete nucleotide sequence of yellow fever virus vaccine strains 17DD and 17D-213. Virus Res. 1995 Jan;35(1):35-41.

33 Lindsey NP, Schroeder BA, Miller ER, Braun MM, Hinckley AF, Marano N, et al. Adverse event reports following yellow fever vaccination. Vaccine. 2008 Nov;26(48):6077-82.

34 Guirakhoo F, Kitchener S, Morrison D, Forrat R, McCarthy K, Nichols R, et al. Live attenuated chimeric yellow fever dengue type 2 (ChimeriVax-DEN2) vaccine: Phase I clinical trial for safety and immunogenicity: effect of yellow fever pre-immunity in induction of cross neutralizing antibody responses to all 4 dengue serotypes. Hum Vaccine. 2006 MarApr;2(2):60-7.

35 Crevat D, Reynolds D, Langevin E, Capeding MR. Safety and immunogenicity of a tetravalent dengue vaccine in Flavivirus-naive and immune Pediatric Populations with Two Vaccination Regimens [abstract]. Am J Trop Med Hyg. 2009;81(5 Suppl 1):S113. Abstract no. 395.

36 Forrat R, Poo JL, Galán-Herrera JF. Immune Response to tetravalent dengue vaccination in Mexican subjects: the effects of Yellow Fever vaccination [abstract]. Am J Trop Med Hyg. 2008;79(6 Suppl):S1 14. Abstract no. 387.

37 Qiao J, Shaw D, Forrat R, Wartel-Tram A, Lang J. Safety, viremia and immunogenicity of sp's VDT in adults previously exposed to live, attenuated flavivirus. In: 13th International Congress on Infectious Diseases. 2008 Jun 19-22; Kuala Lumpur, Malaysia; 2008.

38 Barban V, Mantel M, Gulia S, Girerd Y, Boaz M, Crevat $D$, et al. Evaluation of neutralizing antibody responses against a large range of wild-type isolates in sera of primates vaccinated with CYD TV DEN vaccine. In: 58th Annual meeting of the American Society of Tropical Medicine and Hygiene; 2009 Nov 18-22; Washington DC, USA; 2009. Abstract. no. 394.

39 Green S, Rothman A. Immunopathological mechanisms in dengue and dengue hemorrhagic fever. Curr Opin Infect Dis. 2006 Oct; 19(5):429-36.

40 Halstead SB, O'Rourke EJ. Antibody-enhanced dengue virus infection in primate leukocytes. Nature. 1977 Feb;265(5596):739-41. 
41 Kliks SC, Nisalak A, Brandt WE, Wahl L, Burke D. Antibody-dependent enhancement of dengue virus growth in human monocytes as a risk factor for dengue hemorrhagic fever. Am J Trop Med Hyg. 1989 Apr;40(4):444-51.

42 Mangada MM, Endy TP, Nisalak A, Chunsuttiwat S, Vaughn DW, Libraty DH, et al. Dengue-specific T cell responses in peripheral blood mononuclear cells obtained prior to secondary dengue virus infections in Thai schoolchildren. J Infect Dis. 2002 Jun; 185(12): 1697-703.

43 Mangada MM, Rothman AL. Altered Cytokine Responses of Dengue-Specific CD4 $+\mathrm{T}$ Cells to Heterologous Serotypes. J Immunol. 2005 Aug;175(4):2676-83.

44 Guy B, Nougarede N, Begue S, Sanchez V, Souag N, Carre $M$, et al. Cell-mediated immunity induced by chimeric tetravalent dengue vaccine in naive or flavivirus-primed subjects. Vaccine. 2008 Oct;26(45):5712-21.

45 Mongkolsapaya J, Dejnirattisai W, Xu XN, Vasanawathana S, Tangthawornchaikul N, Chairunsri $A$, et al. Original antigenic sin and apoptosis in the pathogenesis of dengue hemorrhagic fever. Nat Med. $2003 \mathrm{Jul} ; 9(7): 921-7$.

46 Guy B, Barrere B, Malinowski C, Saville M, Teyssour R, Lang J. From research to phase III: preclinical, industrial and clinical development of the sanofi Pasteur tetravalent dengue vaccine. Vaccine. 2011 Sep;29(42):7229-41.

47 Guy B, Chanthavanich P, Gimenez S, Sirivichayakul C, Sabchareon A, Begue $S$, et al. Evaluation by flow cytometry of antibody-dependent enhancement (ADE) of dengue infection by sera from Thai children immunized with a live-attenuated tetravalent dengue vaccine. Vaccine. 2004 Sep;22(27-28):3563-74.

48 Edelman R, Hombach J. "Guidelines for the clinical evaluation of dengue vaccines in endemic areas": summary of a World Health Organization Technical Consultation technical consultation. Vaccine. 2008 Aug;26:(33):4113-9.

49 Thomas SJ, Hombach J, Barrett A. Scientific consultation on cell mediated immunity (CMI) in dengue and dengue vaccine development. Vaccine.
2009 Jan;27(3):355-68.

50 Ministério da Saúde (BR). Secretaria de Vigilância em Saúde. Sistema de Informação de Agravos de Notificação [Internet]. 2011 maio [citado 2011 $\mathrm{m}$ a i o 23 ]. D i s p o nível e m : http://dtr2004.saude.gov.br/sinanweb/tabnet/tab net? sinannet/dengue/bases/denguebrnet.def.

51 Ministério da Saúde (BR). Departamento de Informática do SUS. Informações de Saúde: Epidemiológicas e Morbidade [Internet]. 2011 maio [citado em 2011 maio 25]. Disponível em: http://tabnet.datasus.gov.br/cgi/deftohtm.exe?sih/cn v/nruf.def.

52 Barreto ML, Teixeira MG, Bastos FI, Ximenes RA, Barata RB, Rodrigues LC. Successes and failures in the control of infectious diseases in Brazil: social and environmental context, policies, interventions, and research needs. Lancet. 2011 May; 377(9780): 1877-89.

53 Ministério da Saúde (BR). Secretaria de Vigilância em Saúde, Departamento de Análise de Situação de Saúde. Saúde Brasil 2009 : uma análise da situação de saúde e da agenda nacional e internacional de prioridades em saúde. Brasília: Ministério da Saúde; 2010.

54 Teixeira MG, Costa MC, Coelho G, Barreto ML. Recent shift in age pattern of dengue hemorrhagic fever, Brazil. Emerg Infect Dis. 2008 Oct; 1 4(10): 1663.

55 Ministério da Saúde (BR). Secretaria de Vigilância em Saúde. Isolamento do sorotipo DENV 4 em Roraima / Brasil. Brasilia; 2010. p.1-3. Nota técnica $n^{\circ}$ $110 / 2010$

56 Amarasinghe A, Wichmann O, Margolis HS, Mahoney RT. Forecasting dengue vaccine demand in disease endemic and non-endemic countries. Hum Vaccin. 2010 Sep;6(9):745-53.

Recebido em / Received / Recibido en: 6/8/201 1 Aceito em / Accepted / Aceito en: 16/11/2011 